\title{
Significance of early and late positive responses to insulin hypoglycaemia in patients with intact vagi
}

\author{
G. P. BURNS, ${ }^{1}$ F. C. Y. CHENG ${ }^{2}$ A. G. COX, R. A. PAYNE, \\ J. SPENCER, AND R. B. WELBOURN \\ From the Department of Surgery, Royal Postgraduate Medical School, Ducane Road, \\ and the North Middlesex Hospital, London
}

SUMMARY Insulin tests were performed on 100 subjects with duodenal ulcer who had not undergone surgery. Thirty-seven per cent had 'late' positive responses to insulin. It was suggested that a late response to insulin after surgery was not necessarily an indication of 'adequate' vagotomy.

The secretory responses to insulin before operation revealed no difference in peak acid concentrations or outputs between those with early and late responses. Basal acid concentrations were higher in those with late responses, though the difference was only significant when the division between early and late responses was made at 60 minutes. The distribution of the timing of the peak responses suggested that the division into 'early' and 'late' responders was artificial.

The insulin test is commonly performed to ascertain the completeness of surgical vagotomy for peptic ulcer. When he first introduced the test, Hollander (1948) described certain criteria by which to judge the result. A negative response, indicating complete vagotomy, was one in which acid concentration did not rise above basal values after insulin injection. A positive response, indicating incomplete vagotomy, was one in which acid concentration rose at least $20 \mathrm{~m}$-equiv/l above basal values (or at least $10 \mathrm{~m}$-equiv/1 if basal secretions were anacid). These criteria have been widely accepted, but a number of authorities have suggested alternative criteria although none has met with uncritical approval (Waddell, 1957; Bachrach, 1962; Stempien, 1962; Bank, Marks, and Louw, 1967).

One suggestion has been that there are two types of positive response after vagotomy (Ross and Kay, 1964). The first, described as 'early positive', is seen when Hollander's criteria are fulfilled within 45 minutes of the injection of insulin; this is said to indicate incomplete and inadequate vagotomy. The second, described as 'late positive', is seen when Hollander's criteria are fulfilled later than 45 minutes after the injection of insulin; Ross and Kay (1964) suggested that this might indicate vagotomy which is incomplete but adequate to prevent recurrent

${ }^{1}$ Present address: Department of Surgery, University of New York at Buffalo, Buffalo, New York, USA.

'Present address: Surgical Professorial Unit, Queen Mary Hospital, Hong Kong. peptic ulceration. Several workers have cast doubt on this hypothesis, and Johnston, Thomas, Checketts, and Duthie (1967) have provided important evidence which shows that recurrent ulceration does occur in patients with late positive responses, even when the dividing line between early and late positive responses is taken at 60 minutes after the injection of insulin.

In order to elucidate this problem further, we have studied 100 patients with duodenal ulcer before any operation had been done. All had insulin tests and the results were analysed to see if early and late positive responses occurred even before attempted vagotomy. This was found to be the case and the data were then analysed further to establish whether the pattern of gastric acid secretion varied according to the timing of the response.

\section{PATIENTS AND METHODS}

An insulin test was performed before surgery in 100 subjects with duodenal ulcer. There were 81 men and 19 women. After an overnight fast, a nasogastric tube was positioned in the stomach under radiological control. Fasting gastric juice was aspirated and discarded. Basal secretion was collected for one hour; this was followed by eight 15 -minute collections after the intravenous injection of 20 units of soluble insulin. Aliquots of each specimen were titrated with $\mathrm{N} / 10 \mathrm{NaOH}$ using Topfer's reagent as indicator for free acid.

A positive response to insulin was regarded as a rise in free acid concentration of $20 \mathrm{~m}$-equiv/l or more above 
the basal concentration in any of the 15-minute periods after insulin. These criteria were first applied to men and women alike It has been argued elsewhere (Spencer, Burns, Cheng, Cox, and Welbourn, 1969), however, that it may not be reasonable to apply identical criteria to both sexes when their secretory potential is known to be different; it would be more reasonable to apply lower criteria to women than to men. Therefore the results in females were also analysed using a rise of at least $15 \mathrm{~m}$-equiv/l above basal concentration as the criterion for a positive response.

In each case the timing of the insulin response was noted by recording in which specimen the criterion for a positive response was first fulfilled. It was then possible to divide the patients into those showing 'early positive' and 'late positive' responses, using the 45-minute dividing line described by Ross and Kay (1964) and the one-hour division of Johnston et al (1967).

The following were compared in the patients with early and late positive responses: basal acid concentration and output, rise in acid concentration after insulin, peak acid concentration (the highest concentration achieved in any 15-minute sample), and peak acid output after insulin (as peak half-hour output in m-equiv $\times 2$ ).

\section{RESULTS}

TIMING OF THE POSITIVE RESPONSE TO INSULIN The timing of positive responses is illustrated in Figure 1. In the majority of patients the acid concentration rose to $20 \mathrm{~m}$-equiv/l or more above basal concentration within 45 minutes of the injection of insulin. However, in 37 patients the response occurred later than this, and in 12 it occurred more than one hour after insulin. All subjects who achieved a positive Hollander response did so within 90 minutes of the injection of insulin. In two subjects the response to insulin never fulfilled Hollander's criteria. One was a boy aged 14 years in whom repeated testing revealed unusually high basal acid concentrations (88 m-equiv/l) and output (between 10 and 11 $\mathrm{m}$-equiv/hour). At operation he had two duodenal ulcers; the pancreas appeared normal. The highest

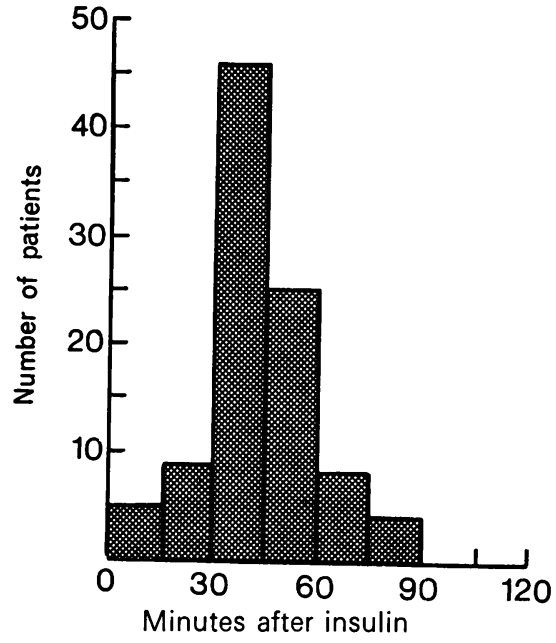

FIG. 1. Frequency distribution diagram showing the numbers of patients who first achieved a positive response to insulin at each 15-minute stage after the injection of insulin. Unoperated males and females with duodenal ulcer are shown. The criteria of Hollander (1948) were used to define a positive response.

rise in acid concentration after insulin was 18 m-equiv/l with a peak in the third specimen; for convenience of analysis he was considered to have an 'early positive' reaction. A second male patient had no free acid in his basal juice nor in any specimen after insulin, although he had a duodenal ulcer confirmed radiologically. He became severely hypoglycaemic during the test which was not repeated. No other tests of gastric secretion were performed and the results in this patient were excluded from our analysis. Without such tests to confirm achlorhydria we hesitate to regard this patient as an example of duodenal ulceration with no acid secretory potential.

Table I shows the proportion of patients who had 'early' or 'late' responses to insulin, as defined by the

TABLE I

INCIDENCE OF POSITIVE RESPONSES TO INSULIN HYPOGLYCAEMIA IN DUODENAL ULCER PATIENTS WITH INTACT VAGI

\begin{tabular}{|c|c|c|c|c|c|c|}
\hline \multirow{3}{*}{$\begin{array}{l}\text { Time Separating } \\
\text { 'Early' and 'Late' } \\
\text { Positive Responses }\end{array}$} & \multirow[t]{3}{*}{ Patients } & \multirow{3}{*}{$\begin{array}{l}\text { No. of } \\
\text { Patients }\end{array}$} & \multicolumn{4}{|c|}{ Number and Incidence of Early and Late Positive Results } \\
\hline & & & \multicolumn{2}{|c|}{ Hollander's Criteria for All } & \multicolumn{2}{|c|}{ Different Criteria for Women ${ }^{1}$} \\
\hline & & & Early Positive & Late Positive & Early Positive & Late Positive \\
\hline 45 minutes after insulin & $\begin{array}{l}\text { All } \\
\text { Men } \\
\text { Women }\end{array}$ & $\begin{array}{l}99 \\
80 \\
19\end{array}$ & $\begin{array}{l}62(63 \%) \\
52(65 \%) \\
10(53 \%)\end{array}$ & $\begin{array}{c}37(37 \%) \\
28(35 \%) \\
9(47 \%)\end{array}$ & $\begin{array}{l}65(66 \%) \\
52(65 \%) \\
13(68 \%)\end{array}$ & $\begin{array}{c}34(34 \%) \\
28(35 \%) \\
6(32 \%)\end{array}$ \\
\hline 60 minutes after jnsulin & $\begin{array}{l}\text { All } \\
\text { Men } \\
\text { Women }\end{array}$ & $\begin{array}{l}99 \\
80 \\
19\end{array}$ & $\begin{array}{l}87(88 \%) \\
71(89 \%) \\
16(84 \%)\end{array}$ & $\begin{array}{r}12(12 \%) \\
9(11 \%) \\
3(16 \%)\end{array}$ & $\begin{array}{l}89(90 \%) \\
71(89 \%) \\
18(95 \%)\end{array}$ & $\begin{array}{c}10(10 \%) \\
9(11 \%) \\
1(5 \%)\end{array}$ \\
\hline
\end{tabular}

${ }^{1}$ Hollander's criteria for men and lower criteria for women. 
TABLE II

DIFFERENCES IN ACID SECRETION BETWEEN PATIENTS WITH 'EARLY' AND 'LATE' POSITIVE RESPONSES TO INSULIN HYPOGLYCAEMIA

\begin{tabular}{|c|c|c|c|c|c|c|c|}
\hline & & \multirow{2}{*}{$\begin{array}{l}\text { No. of } \\
\text { Patients }\end{array}$} & \multicolumn{3}{|c|}{ Mean Acid Concentration $\pm S D(m-e q u i v / l)$} & \multicolumn{2}{|c|}{ Mean Acid Output $\pm S D(m-e q u i v / h r)$} \\
\hline & & & Basal & Peak & Rise & Basal & Peak \\
\hline \multicolumn{8}{|c|}{ Using 45-minute division } \\
\hline Men & $\begin{array}{l}\text { Early positive } \\
\text { Late positive }\end{array}$ & $\begin{array}{l}52 \\
28\end{array}$ & $\begin{array}{l}28.9 \pm 19.7 \\
36.8 \pm 28.8\end{array}$ & $\begin{array}{l}103 \cdot 8 \pm 17 \cdot 1 \\
104 \cdot 1 \pm 29 \cdot 5\end{array}$ & $\begin{array}{l}73 \cdot 3 \pm 21 \cdot 0 \\
64 \cdot 3 \pm 24 \cdot 1\end{array}$ & $\begin{array}{l}3.2 \pm 3 \cdot 5 \\
3.9 \pm 4.0\end{array}$ & $\begin{array}{l}26 \cdot 1 \pm 17 \cdot 3 \\
28.9 \pm 16 \cdot 4\end{array}$ \\
\hline Women & $\begin{array}{l}\text { Early positive } \\
\text { Late positive }\end{array}$ & $\begin{array}{r}10 \\
9\end{array}$ & $\begin{array}{l}21.9 \pm 19 \cdot 0 \\
28.1 \pm 20.8\end{array}$ & $\begin{array}{l}87 \cdot 7 \pm 25.0 \\
91 \cdot 3 \pm 19.5\end{array}$ & $\begin{array}{l}68.0 \pm 19.3 \\
58.7 \pm 20.7\end{array}$ & $\begin{array}{l}1.8 \pm 1.8 \\
2.6 \pm 2.5\end{array}$ & $\begin{array}{l}16 \cdot 1 \pm 8.8 \\
15 \cdot 7 \pm 12 \cdot 4\end{array}$ \\
\hline \multicolumn{8}{|c|}{ Using 60-minute division } \\
\hline Men & $\begin{array}{l}\text { Early positive } \\
\text { Late positive }\end{array}$ & $\begin{array}{r}71 \\
9\end{array}$ & $\begin{array}{l}31 \cdot 2 \pm 23 \cdot 0 \\
53 \cdot 2 \pm 33 \cdot 1^{1}\end{array}$ & $\begin{array}{l}104 \cdot 0 \pm 22.0 \\
104 \cdot 0 \pm 26.3\end{array}$ & $\begin{array}{l}72.7 \pm 20.8 \\
50.8 \pm 26.6^{1}\end{array}$ & $\begin{array}{l}3.5 \pm 3.8 \\
0.8 \pm 2.6\end{array}$ & $\begin{array}{l}27 \cdot 1 \pm 17.4 \\
27.0 \pm 13.9\end{array}$ \\
\hline Women & $\begin{array}{l}\text { Early positive } \\
\text { Late positive }\end{array}$ & $\begin{array}{r}16 \\
3\end{array}$ & $\begin{array}{l}20.3 \pm 17.0 \\
56.0 \pm 16.4^{2}\end{array}$ & $\begin{array}{l}89 \cdot 1 \pm 23 \cdot 3 \\
92.0 \pm 15 \cdot 6\end{array}$ & $\begin{array}{l}68.7 \pm 16.8 \\
36.0 \pm 12.5^{2}\end{array}$ & $\begin{array}{l}1 \cdot 7 \pm 1 \cdot 8 \\
4 \cdot 6 \pm 2 \cdot 7^{1}\end{array}$ & $\begin{array}{l}17.0 \pm 10.8 \\
10.4 \pm 2.0\end{array}$ \\
\hline
\end{tabular}

${ }^{1}$ A significant difference at the $5 \%$ level between the early and late positive groups.

'A significant difference at the $1 \%$ level between the early and late positive groups.

45- and the 60-minute limit. Using Hollander's criteria only $63 \%$ of subjects had a positive response with 45 minutes. When the 60 -minute limit was used to define early responses, the incidence was higher $(88 \%)$.

The incidence of early responses was greater in men than in women, though the difference was not significant. When the results in men were analysed by Hollander's criteria and lower criteria were used for analysis of the results in women (Spencer et al, 1969) the difference in the incidence of early responses between the two sexes was virtually eliminated.

CHARACTERISTICS OF THE RESPONSE TO INSULIN IN THE 'EARLY' AND 'LATE' RESPONDERS The basal acid concentration and output, the rise in acid concentral tion, peak concentration, and peak output after insulin in the patients with 'early' and 'late' responses to insulin, as defined by Ross and Kay (1964) and by Johnston et al (1967), were compared (Table II). The results may be summarized as follows:

Basal acid concentrations were consistently higher in the 'late positive' group; when the one-hour division was used the difference between the groups was significant.

Peak concentrations were very similar in all groups, with no significant differences.

The rise in acid concentration after insulin was greater in the 'early positive' group, the difference being significant when the one-hour division was used.

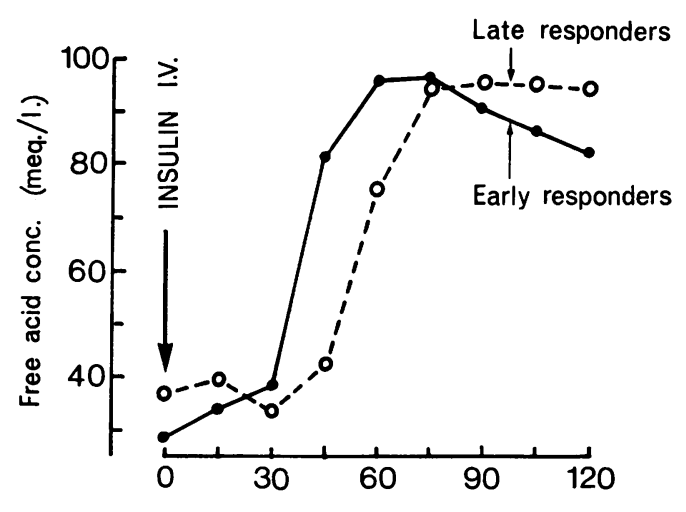

Minutes after insulin

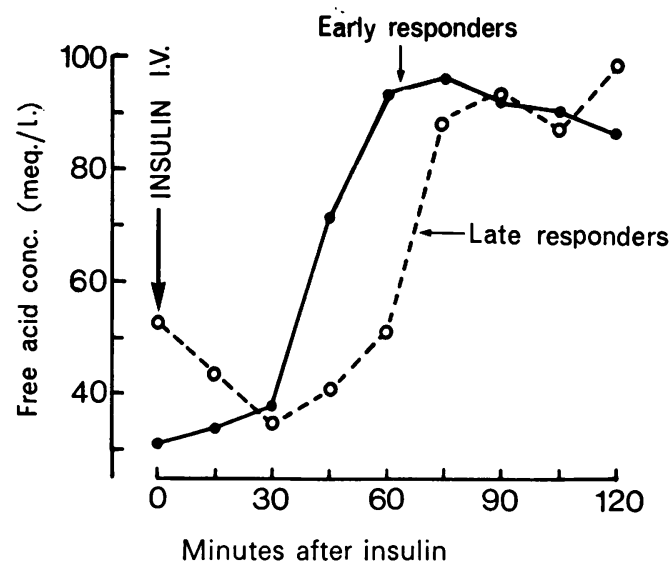

FIG. $2 b$.

FIG. 2a.

FIG. 2. Changes in mean gastric acid concentration after the injection of insulin in 80 unoperated males with duodenal ulcer, divided into those with positive responses before and later than 45 minutes (a), and 60 minutes (b), after the injection of insulin. 
Basal acid outputs showed no consistent trend, but in women the 'late positive' group had a significantly higher result when the one-hour division was used. By contrast the men in the 'late' group had a lower basal output, though the difference was not significant.

Peak acid outputs were similar in the 'early' and 'late' groups.

Changes in acid concentration in the two groups are recorded graphically in Figs. $2 a$ and $b$, which represent a 45-minute and 60-minute division respectively into 'early' and 'late' groups. The type of response was almost identical in the two groups except for its timing. The rise in concentration was equally steep in the two groups.

The timing of the peak concentrations in all males taken together is illustrated in Figure 3. This shows a single peak with a 'skew' distribution which might be anticipated after a single injection of insulin. Had the two groups of patients been inherently different a double peak would be expected; this was not the case.

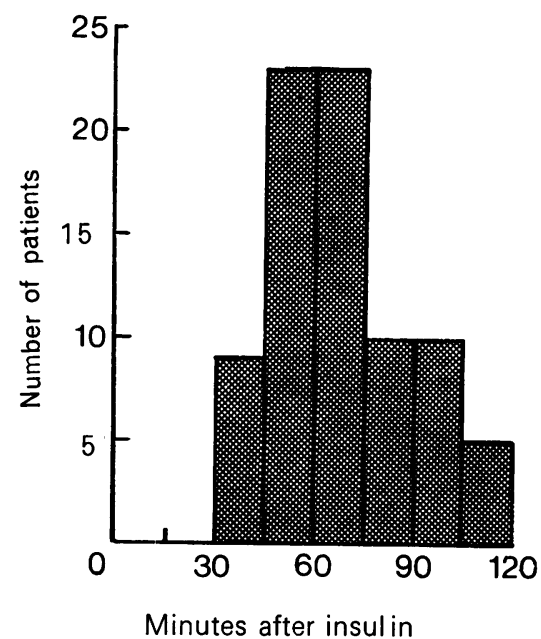

FIG. 3 Frequency distribution diagram showing the timing of the peak acid concentration in 80 unoperated males with duodenal ulcer subjected to the insulin test.

DISCUSSION

The finding that nearly $40 \%$ of patients with unoperated duodenal ulcers had late positive responses to insulin indicates that such a response can occur in association with 'unsafe' levels of acid secretion. This suggests that a similar response to insulin after surgery cannot be held to indicate 'adequate' vagotomy. The same inference can be drawn from the $24 \%$ incidence of recurrent ulcers in patients with late insulin responses, reported by Johnston et al (1967).

Ross and Kay (1964) found that patients with late responses to insulin after vagotomy had a greater mean reduction in the augmented histamine response compared with preoperative values than did those with early responses. Johnston et al (1967) found that the incidence of recurrent ulceration was $68 \%$ in those with early responses but only $24 \%$ in the late responders. It was therefore of interest to see whether the gastric secretory patterns of patients with intact vagi who had early insulin responses differed from those in patients with late responses.

When the 45-minute division of Ross and Kay (1964) was used, no significant difference was found. When the 60-minute division of Johnston et al (1967) was used, basal acid concentrations were significantly higher in the 'late positive' groups; this was associated with a significantly smaller rise in acid concentration after insulin, the peak concentration being almost identical. The even distribution of the timing of the Hollander response and of the peak acid concentrations suggested that the division into early and late responders was artificial and did not reflect any basic biological difference. This was consistent with the similar changes in acid concentration after insulin in the two groups. It may be that the late positive pattern was simply a reflection of higher basal concentrations, for it may be that subjects with a high 'vagal' tone under basal conditions require more prolonged stimulation before achieving a 'positive' response. The difference in basal concentrations, however, was only significant when the one-hour division into 'early' and 'late' groups was used.

It is of interest to speculate whether any positive response to insulin would indicate 'adequate' vagotomy. Our own data suggest that all patients with an intact vagus who achieve a positive Hollander response do so within 90 minutes of the administration of insulin. It may be argued that after vagotomy a response later than this might indicate adequate surgery. However, study of a larger group of patients might reveal a few with insulin responses even later than those found in this study.

It was also of interest that the different incidence of early positive responses in men and women disappeared when the lower criterion for a positive response in women was used. This is in accord with the concept, established on a different basis, that different criteria for interpretation of insulin tests should be used in men and women (Spencer et al, 1969).

We gratefully acknowledge a research grant from the NE Metropolitan Regional Board, help with the tests from staff nurses Pope and Shearman, and from Mrs Delores Rigby. 


\section{REFERENCES}

Bachrach, W. M. (1962). Laboratory criteria for the completeness of vagotomy. Amer. J. dig. Dis., 7, 1071-1085.

Bank, S., Marks, I. N., and Louw, J. H. (1967). Histamine- and insulin-stimulated gastric acid secretion after selective and truncal vagotomy. Gut, 8, 36-41.

Hollander, F. (1948). Laboratory procedures in the study of vagotomy (with particular reference to the insulin test). Gastroenterology, 11, 419-425.

Johnston, D., Thomas, D. G., Checketts, R. G., and Duthie, H. L.
(1967). An assessment of postoperative testing for completeness of vagotomy. Brit. J. Surg., 54, 831-833.

Ross, B., and Kay, A. W. (1964). The insulin test after vagotomy. Gastroenterology, 46, 379-386.

Spencer, J.. Burns, G. P., Cheng, F. C. Y., Cox, A. G., and Welbourn, R. B. (1969). Differences between males and females in the Hollander insulin test. Gut, 10, 307-310.

Stempien, S. J. (1962). Insulin gastric analysis: technic and interpretations. Amer. J. dig. Dis., 7, 138-152.

Waddell, W. R. (1957). The acid secretory response to histamine and insulin hypoglycemia after various operations on the stomach. Surgery, 42, 652-658.

\section{The September 1969 Issue}

\section{THE AUGUST 1969 ISSUE CONTAINS THE FOLLOWING PAPERS}

Differential ferrioxamine test in haemochromatosis and liver disease MICHAEL BARRY, GUISEPPE CARTEI, and SHEILA SHERLOCK

Postmortem study of the frequency of gallstones in patients with cirrhosis of the liver IAN A. D. BOUCHIER

Significance of increased 'splenic uptake' on liver scintiscanning A. L. W. F. EDDLESTON, L. M. BLENDIS, S. B. OSBORN, and ROGER WILLIAMS

Effect of cholestyramine on the absorption of vitamin $D_{3}$ and calcium $W$. GRANT THOMPSON and GILBERT $R$. THOMPSON

Gastrointestinal motility and gastric secretion during intravenous infusions of gastrin II J. J. MISIEWICZ, SHEILA L. WALLER, and D. J. HOLDSTOCK

Action of gastrin on the lower oesophageal sphincter in man G. R. GILES, M. C. MASON, C. HUMPHRIES, and C. G. CLARK

Diffuse hypertrophy of gastric mucosa (Menétrier's disease) and iron-deficiency anaemia A. K. SINGH, R. C. CUMARASWAMY, and B. CORRIN
Reversibility of radiological appearances during clinical improvement in colonic Crohn's disease J. HYWEL JONES, J. E. LENNARD-JONES, and A. C. YOUNG

Response to insulin of the intact stomach in patients with duodenal ulcer G. GILLESPIE, I. E. GILLESPIE, and A. W. KAY

Effect of acid infusion into various levels of the intestine on gastric and pancreatic secretion in the cat $\mathbf{s}$. J. KONTUREK, J. DUBIEL, and B. GABRYS

Estimation of faecal fat excretion using cuprous thiocyanate as a continuous marker M. F. LEE, J. M. TEMPERLEY, and M. DICK

\section{Techniques}

The short pentagastrin test in the investigation of gastric disease J. R. KIRKPATRICK, J. H. LAWRIE, A. P. M. FORREST, and H. CAMPBELL

\section{Progress report}

Why use gastric cytology? E. G. CANTRELL

Notes and activities

Copies are still available and may be obtained from the PUBLISHING MANAGER, BRITISH MEDICAL ASSOCIATION, TAVISTOCK SQUARE W.c.1. price 17s. 6D. 